\title{
Repair of astrocytes, blood vessels, and myelin in the injured brain: possible roles of blood monocytes
}

Hey-Kyeong Jeong ${ }^{1,2,3}$, Kyung-min Ji ${ }^{1,2,3}$, Jun Kim ${ }^{1,2,3}$, Ilo Jou ${ }^{1,2,4}$ and Eun-Hye Joe $e^{1,2,3,4^{*}}$

\begin{abstract}
Inflammation in injured tissue has both repair functions and cytotoxic consequences. However, the issue of whether brain inflammation has a repair function has received little attention. Previously, we demonstrated monocyte infiltration and death of neurons and resident microglia in LPS-injected brains (Glia. 2007. 55:1577; Glia. 2008. 56:1039). Here, we found that astrocytes, oligodendrocytes, myelin, and endothelial cells disappeared in the damage core within 1-3 $d$ and then re-appeared at 7-14 $d$, providing evidence of repair of the brain microenvironment. Since round $\mathrm{Iba}-1^{+} / \mathrm{CD} 45^{+}$monocytes infiltrated before the repair, we examined whether these cells were involved in the repair process. Analysis of mRNA expression profiles showed significant upregulation of repair/resolution-related genes, whereas proinflammatory-related genes were barely detectable at $3 \mathrm{~d}$, a time when monocytes filled injury sites. Moreover, Iba- $1^{+} / \mathrm{CD} 45^{+}$cells highly expressed phagocytic activity markers (e.g., the mannose receptors, CD68 and LAMP2), but not proinflammatory mediators (e.g., iNOS and IL1 $\beta$ ). In addition, the distribution of round $\mathrm{Iba}-1^{+} / \mathrm{CD} 45^{+}$cells was spatially and temporally correlated with astrocyte recovery. We further found that monocytes in culture attracted astrocytes by releasing soluble factor(s). Together, these results suggest that brain inflammation mediated by monocytes functions to repair the microenvironment of the injured brain.
\end{abstract}

Keywords: Brain inflammation, Repair, Brain microenvironment

\section{Background}

Brain inflammation accompanied by brain injury has been a focus of research efforts because of its possible roles in the onset and progression of a number of neurodegenerative diseases. However, most brain inflammation studies have focused on neurons, and little information on how brain inflammation affects other brain cells, including astrocytes and oligodendrocytes, is available. Astrocytes function to maintain the homeostasis of the brain microenvironment by taking up potassium, glutamate, and water from the extracellular space, and supplying nutrients and growth factors to neurons (for review, see [1]). Oligodendrocytes myelinate axons, allowing for rapid propagation of action potentials to axon terminals.

\footnotetext{
*Correspondence: ehjoe@ajou.ac.kr

${ }^{1}$ Neuroscience Graduate Program, Department of Biomedical Sciences, Ajou University School of Medicine, Suwon, Kyunggi-do 443-721, Korea ${ }^{2}$ Department of Pharmacology, Ajou University School of Medicine, Suwon, Kyunggi-do 443-721, Korea

Full list of author information is available at the end of the article
}

Therefore, it is important to know how these cells respond to brain injury.

Studies of systemic inflammation showed that inflammation has dual functions: a cytotoxic function to kill infected microbes and a repair function to regenerate damaged tissues $[2,3]$. In the presence of proinflammatory stimulators such as IFN- $\gamma$, monocytes/macrophages are classically activated and protect the tissue from infection by producing cytotoxic inflammatory molecules $[4,5]$. On the other hand, in the presence of IL-4 and IL-13, monocytes/macrophages are alternatively activated, and produce several molecules that are involved in antiinflammation and repair/regeneration [6-9]. Therefore, in myocardial injury, monocytes/macrophages rapidly remove cell debris and lead to myofibroblast infiltration and collagen deposition through production of high levels of TGF- $\beta$ and VEGF-A [8]. In injured skin, macrophage depletion causes delays in healing processes $[10,11]$.

Previously, we reported that in lipopolysaccharide (LPS) - or ATP-injected brain and contusion-induced 
spinal cord, resident microglia as well as neurons die in the damage core and monocytes appear and fill the damage core [12-15]. In the ischemic brain, infiltration of blood monocytes has been reported [16,17]. However, it is not clear how monocytes contribute to brain inflammation and what occurs after monocytes infiltrate into the injured brain.

In the present study, we examined how astrocytes, oligodendrocytes, and endothelial cells respond to damage in the LPS-injected substantia nigra (SN), a Parkinson's disease-related brain area where LPS induces significant damage [13]. We also examined the roles of infiltrating monocytes in the injured brain. The results of this study showed that damage to astrocytes, oligodendrocytes, and endothelial cells peaked at approximately $3 \mathrm{~d}$. However, these cells recovered 7-14 $\mathrm{d}$ after infiltration from the blood of round Iba- $1^{+} / \mathrm{CD} 45^{+}$monocytes. Importantly, these monocytes expressed repair/regeneration-related genes, suggesting that they may function to repair the damaged brain.

\section{Results}

\section{Recovery of the damaged microenvironment in the} injured brain

Since most studies of brain injury have focused on neuronal damage, knowledge is limited on how other brain cells behave in the injured brain. In the present study, we first examined the time-dependent responses of brain cells, including astrocytes, endothelial cells, oligodendrocytes (by examining myelin) and inflammatory cells, in the injured brain. To achieve this, LPS ( $5 \mu \mathrm{g}$ in $2 \mu \mathrm{l}$ PBS) was injected into the substantia nigra pars compacta $(\mathrm{SNpc})$; this region was chosen based on our previous observation that LPS induces significant damage to the SNpc but not to the cortex [13].

In the intact brain, the density of $\mathrm{GFAP}^{+}$astrocytes (arrows in Figure 1Ab) differs among regions; within the $\mathrm{SN}$, it is low in the $\mathrm{SNpc}$ and high in the substantia nigra pars reticulata ( $\mathrm{SNr}$ ) (Figure 1Aa-c). LPS injection into the SNpc induced the death of astrocytes within $12 \mathrm{~h}$ (Figure $1 \mathrm{Ag}, \mathrm{h}$ ), as we and others have previously reported $[13,18]$. At $1-3 \mathrm{~d}, \mathrm{GFAP}^{+}$astrocyte-empty areas were significantly expanded (Figure $1 \mathrm{Aj}-\mathrm{o}$ ). In the $\mathrm{SNr}$, the number of astrocytes was reduced on day 1 (Figure $1 \mathrm{Al}$ ), and these cells almost disappeared by day 3 (Figure 1Ao). In response to PBS-injection, astrocytes became activated - the number of astrocyte processes increased and the processes became longer and thicker (arrow in Figure 1Ae) - but death did not occur (Figure 1Ad-f). Interestingly, however, the impaired astrocytes recovered between 7 and $14 \mathrm{~d}$, although they exhibited a highly activated morphology (Figure 1Ar, t, u). At $2 \mathrm{mo}$, astrocytes filled the damaged areas almost completely (Figure 1Av), although these cells were still activated (arrows in Figure 1Aw, x).
The disappearance and reappearance of $\mathrm{GFAP}^{+}$astrocytes were not merely due to reduced GFAP immunoreactivity since other markers of astrocytes in addition to GFAP, including S100 $\beta\left(\mathrm{Ca}^{2+}\right.$-binding protein), EAAT1 (GLAST, excitatory amino acid transporter 1 ) and Kir4.1 (potassium channel), also disappeared at $3 \mathrm{~d}$ (Figure 1B-D) and reappeared at $14 \mathrm{~d}$ (arrows in Figure 1B-D). The areas in which each marker was absent were measured and plotted (Figure 1E-H). Using Nissl staining, we verified the death of astrocytes at $1 \mathrm{~d}$ (Additional file 1: Figure S1).

We next examined oligodendrocytes and myelin. $\mathrm{CC}-1^{+}$ oligodendrocytes were injured at $3 \mathrm{~d}$ and gradually recovered beginning on day 7 (Figure 2A). Similarly, the decrease in Eriochrome Cyanine RC (ECRC)-stained myelin also reached a peak at 3-7 d, but gradually recovered at $14 \mathrm{~d}$ and 2 mo (Figure 2B, D). Blood vessels with SMI $71^{+}$endothelial cells disappeared in the injection core at 3 $\mathrm{d}$ after LPS injection, but reappeared at $14 \mathrm{~d}$, and seemed to be almost intact at 2 mo (Figure 2C, D). Interestingly, the neuron-damage area detected by $\mathrm{MAP}^{+}$dendrites reached a peak at $3 \mathrm{~d}$ and was maintained and/or slightly decreased at $7 \mathrm{~d}$ before decreasing gradually at later time points (14 d and $2 \mathrm{mo}$ ) (Figure 3A, B). TH-positivity also showed a similar pattern. In the contralateral (contra) side and in PBS-injected controls, $\mathrm{TH}^{+}$dopaminergic neuronal cell bodies were detectable (Figure 3C, white arrows), but both $\mathrm{TH}^{+}$dopaminergic neuronal cell bodies and processes were injured at $3 \mathrm{~d}$ after LPS injection. Notably, however, only processes (white arrowheads), but not cell bodies, reappeared at $14 \mathrm{~d}$ and $2 \mathrm{mo}$ (Figure 3C). These results suggest that brain microenvironmental damage (damage to astrocytes, oligodendrocytes, myelin, blood vessels, and neurites) actively recovers in the injured brain.

\section{Astrocytes and oligodendrocytes proliferate and migrate toward the damage}

We further examined whether the impaired astrocytes could be recovered by cell proliferation. Cells expressing Ki-67 (a cell cycle protein used as a proliferation marker) significantly increased from $3 \mathrm{~d}$ (Figure 4A), while Ki-67 cells were barely detectable in intact SNpc and at $1 \mathrm{~d}$ after LPS injection (Figure 4A). In double-labeling experiments, proliferating $\mathrm{Ki}^{+} 7^{+}$cells were merged with $\mathrm{GFAP}^{+}$and/or vimentin $^{+}$astrocytes (Figure 4B). In addition, Ki67 immunoreactivity was found in Olig2 ${ }^{+}$cells, which are considered progenitor cells of oligodendrocytes and astrocytes, as well as in reactive astrocytes [19,20] (Figure 4B). Interestingly, Olig2 was detected in either the nucleus (arrows) or cytosol (arrowheads) of $\mathrm{GFAP}^{+}$or vimentin ${ }^{+}$astrocytes and CC-1 ${ }^{+}$ oligodendrocytes $7 \mathrm{~d}$ after LPS injection (Figure 4C). These findings suggest that astrocytes and oligodendrocytes proliferate and fill in astrocyte- and oligodendrocyte-deficient regions in the LPS-injected SNpc. 


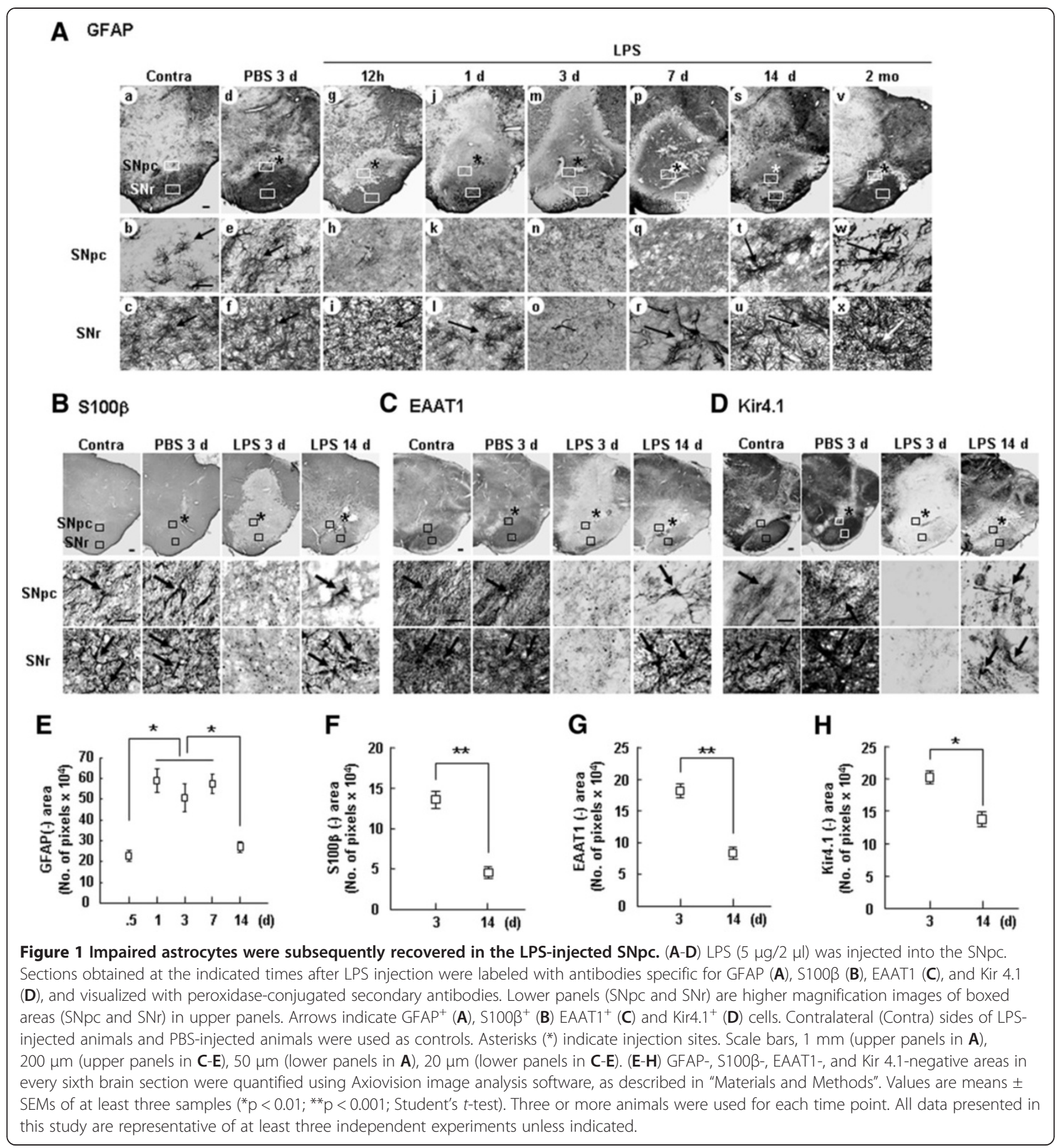

Possible involvement of brain inflammation in repair of damaged microenvironment of the brain

Because an important role of inflammation is to repair damaged tissue $[8,10]$ we examined whether brain inflammation could contribute to the repair of damage to the brain microenvironment. Previously, we reported that ramified $\mathrm{Iba}-1^{+}$resident microglia died in injured brain and spinal cord, and that round Iba- $1^{+}$monocytes infiltrated into these tissues [12-15].
In this study, we found that in LPS-injected brain, the number of round $\mathrm{Iba}-1^{+}$cells was markedly increased at $3 \mathrm{~d}$, but subsequently decreased between 3 and $7 \mathrm{~d}$ (Figure 5A, B). In the SNpc, the decrease in the number of round Iba- $1^{+}$cells at $7 \mathrm{~d}$ appeared to be due to the death of a portion of these cells, since some round Iba- $1^{+}$cells were positive in TUNEL assays (lower panels 'SNpc' in Figure 5A, Additional file 2: Figure S2). In $\mathrm{SNr}$ areas, Iba- $1^{+}$cells became ramified and highly expressed 


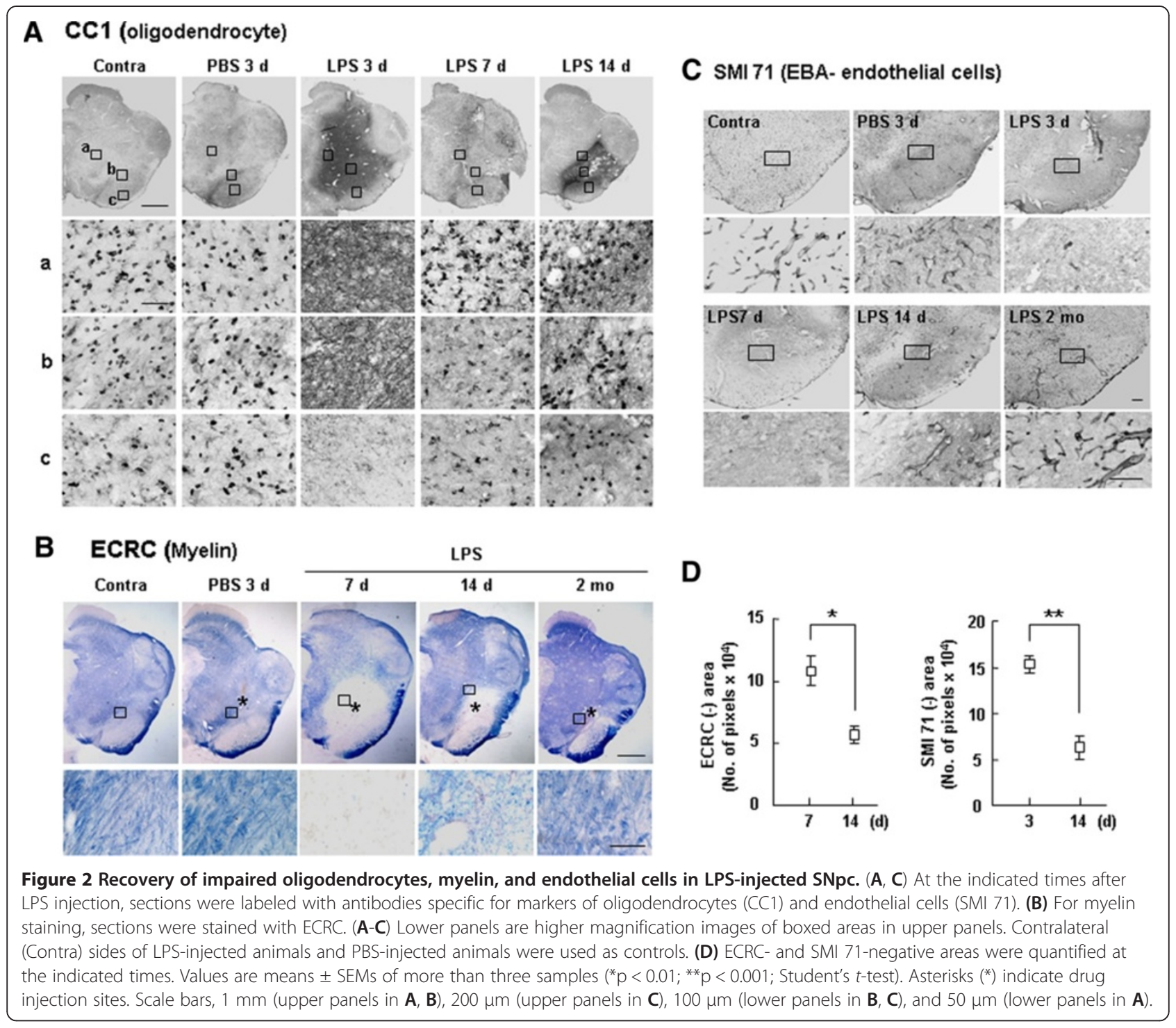

Iba-1 at $7 \mathrm{~d}$ (lower panels 'SNr' in Figure 5A, white arrows). In the intact brain, the density of Iba- $1^{+}$microglia was low in the SNpc and high in the $\mathrm{SNr}$, as shown in the contralateral (Contra) side. We speculate that, during repair processes, more monocytes survive in the $\mathrm{SNr}$ and become resident microglia. Additionally, round $\mathrm{Iba}-1^{+}$ cells were not detectable in the PBS-injected brain (Figure 5A). Round $\mathrm{CD} 45^{+}$cells also appeared approximately $1 \mathrm{~d}$ after LPS injection whereas they were not detectable in intact and PBS-injected brains (Figure 5C). Particularly, these $\mathrm{CD} 45^{+}$cells were found around blood vessels (BV) with high densities (inset in Figure $5 \mathrm{C}$ lower panel ' $a$ '). The number of $\mathrm{CD} 45^{+}$cells and their recruited area also reached a maximum at $3 \mathrm{~d}$, and then progressively decreased through to $7 \mathrm{~d}$ (Figure 5C). Double-labeling experiments additionally showed CD45 immunoreactivity in round $\mathrm{Iba}-1^{+}$cells in the ipsilateral sides at $3 \mathrm{~d}$ (arrowheads in Figure 5D) but not in ramified Iba- $1^{+}$cells in the contralateral sides (arrows in Figure 5D). It has been reported that monocytes highly express Iba-1 and CD45, whereas resident microglia express Iba- 1 but weakly and barely express CD45 [12,14,21-24] (Table 1). Previously, we reported that labeled monocytes transplanted into the tail vein were found in the damage core in LPS-injected brains [12]. Therefore, based on these lines of evidence, we considered the round $\mathrm{Iba}-1^{+}$and/or $\mathrm{CD} 45^{+}$cells as monocytes.

Next, using a microarray, we examined mRNA expression patterns at times before $(6 \mathrm{~h})$ and after $(3 \mathrm{~d})$ infiltration of monocytes, respectively. At $6 \mathrm{~h}$, mRNA expression of cytokines (IL1B, TNF, IL6), chemokines (CCL2, 3, 4, 7, CXCL 10 and 11), and transcription factors that regulate biosynthesis of cytokines and chemokines (IRF3, 7, and 9) significantly increased in the LPS-injected brain, but 
A

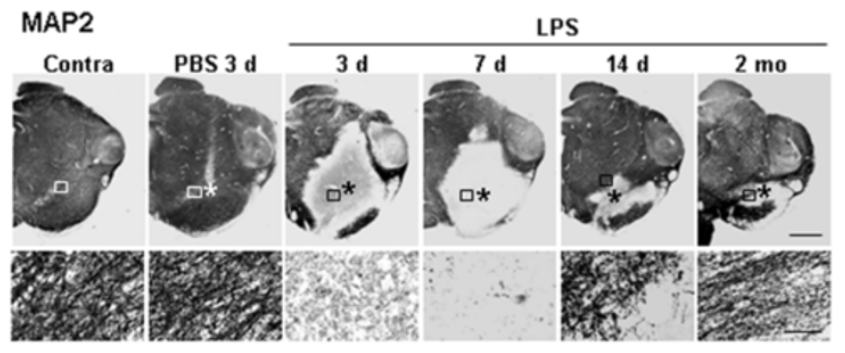

C $_{\mathrm{TH}}$

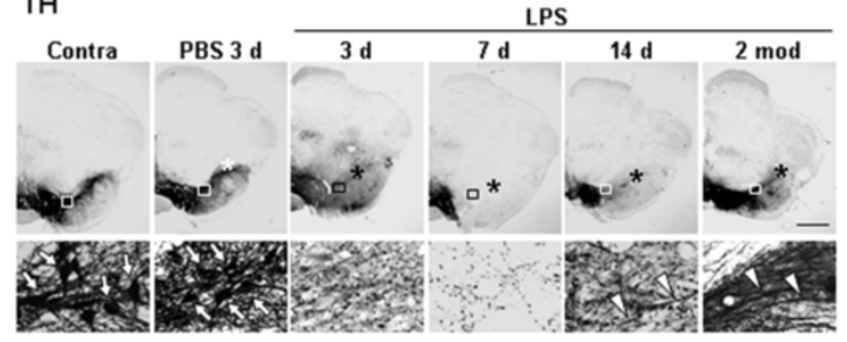

B

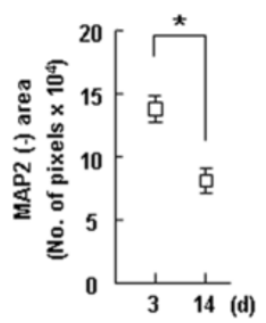

Figure 3 Recovery of impaired neurites in LPS-injected SNpc. (A, C) At the indicated times after LPS injection, sections were labeled with antibodies specific for markers of MAP2 (A) and tyrosine hydroxylase (TH) (C). Lower panels are higher magnification images of boxed areas in upper panels. Arrows in lower panels in (C) indicate $\mathrm{TH}^{+}$cell bodies. (B) MAP2-negative areas at 3 and $14 \mathrm{~d}$ after LPS injection were quantified. Values are means \pm SEMs of more than three samples $\left({ }^{*} p<0.01\right.$; Student's $t$-test). Asterisks $\left(^{*}\right)$ indicate injection sites. (C) In contralateral (contra) sides and PBS-injected brains, $\mathrm{TH}^{+}$dopaminergic neuronal cell bodies were detectable (white arrows), but $\mathrm{TH}^{+}$dopaminergic neuronal cell bodies and processes were injured at $3 \mathrm{~d}$ after LPS injection. At $14 \mathrm{~d}$ and $2 \mathrm{mo}$, only processes reappeared (white arrowheads). Scale bars, $1 \mathrm{~mm}$ (upper panels in $\mathbf{A}, \mathbf{C}$ ), and $100 \mu \mathrm{m}$ (lower panels in $\mathbf{A}, \mathbf{C}$ ).

barely increased at $3 \mathrm{~d}$ (Figure 6A). In contrast, expression of genes associated with anti-inflammation (IL1RN, TGFB1, TGFBI, TGFBR1, IL10RA, IL10RB), phagocytosis (COLEC12, CD36, SCARB1, FCGR1), and wound healing (TGFB1, TGFBR2, PF4, VWF, COL3A1) were significantly increased at $3 \mathrm{~d}$, but were barely elevated or decreased at $6 \mathrm{~h}$ after LPS injection (Figure 6B).

We further analyzed gene expression by RT-PCR, focusing on the expression of two prominent inflammatory mediators, TNF- $\alpha$ and iNOS, and two markers of repair/resolution-related genes, mannose receptor (MR) and TGF- $\beta 1$ [7]. In the LPS-injected brain, expression of TNF- $\alpha$ and iNOS mRNA increased at times before infiltration of monocytes ( 3 and $12 \mathrm{~h}$ ) compared with the PBS-injected brain, but was barely detectable at $1 \mathrm{~d}$ and thereafter (Figure 7A, B). On the other hand, mRNA expression of MR significantly increased from $1 \mathrm{~d}$, and was maintained at an elevated level for up to $14 \mathrm{~d}$ (Figure 7A, B). TGF- $\beta 1$ mRNA levels slightly increased in LPS-injected brain at $12 \mathrm{~h}-1 \mathrm{~d}$ after LPS injection, and remained elevated for up to $14 \mathrm{~d}$ (Figure 7A, B). Taken together, these results suggest that gene expression patterns in LPS-injected SN after monocyte infiltration show repair/resolution-related function rather than proinflammatory and/or neurotoxic function.
Next, we used double-immunolabeling to examine whether monocytes expressed proinflammatory genes and repair/resolution-related genes in the injured brain. Depending on the sources of antibodies used to examine expression of proteins, microglia and/or monocytes were identified by staining for Iba-1, CD11b, or CD45 in these cells (Table 1). Expression of iNOS, a major inflammatory mediator, was detected in myeloperoxidase (MPO) ${ }^{+}$ neutrophils at $12 \mathrm{~h}$ to $1 \mathrm{~d}$ after LPS injection, but not in $\mathrm{CD}_{11 \mathrm{~b}^{+}}$or $\mathrm{CD}_{4} 5^{+}$cells (Figure $7 \mathrm{C}$ ), as we previously reported [12]. IL-1 $\beta$ expression was detected in ramified Iba- $1^{+}$cells at $3 \mathrm{~h}$ (Figure 7D). However, round CD $45^{+}$ and Iba- $1^{+}$cells expressed neither iNOS nor IL-1 $\beta$ at 3$7 \mathrm{~d}$ (Figure 7D). Interestingly, most round CD $45^{+}$cells expressed mannose receptor (MR), which is known to play important roles in endocytosis/phagocytosis $[25,26]$ (Figure 7E). In addition, round but not ramified Iba- $1^{+}$ cells highly expressed CD68, an indicator of lysosomal enzyme activity that is considered a marker of phagocytic activity [27] (Figure 7F). Round $\mathrm{CD} 11 \mathrm{~b}^{+}$cells also highly expressed LAMP2 (Figure 7G), a lysosomal protein that participates in the fusion of lysosomes and phagosomes [28]. Since these monocytes have strong phagocytic activity, they may scavenge damaged cells and debris in the injured brain. These results suggest 


\section{A Ki67 (proliferating cells)}

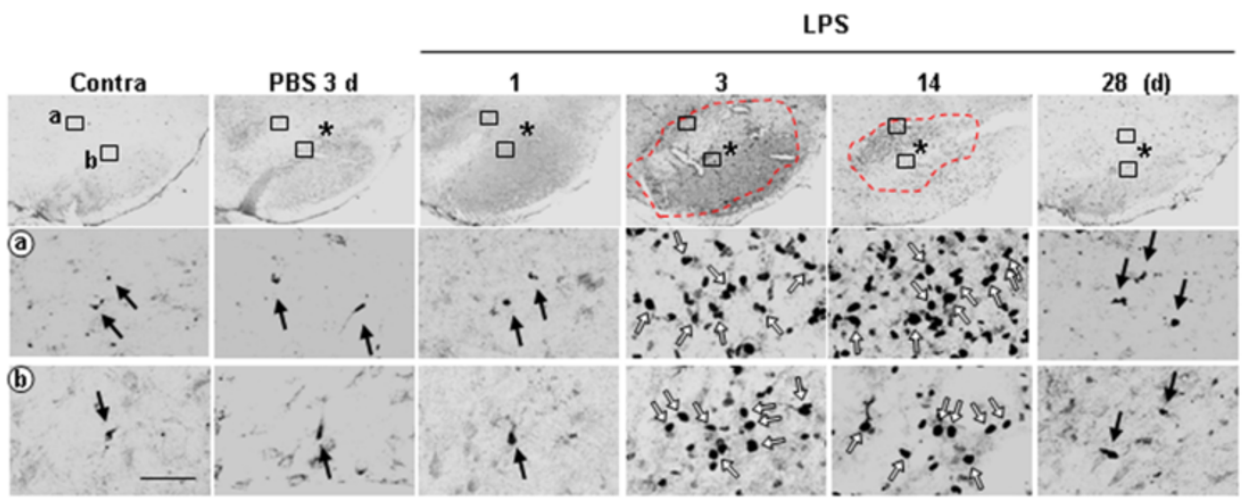

B

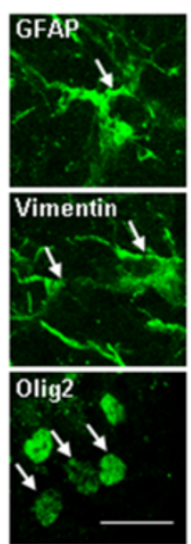

Ki67
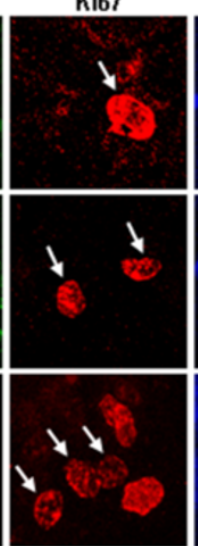

DAPI
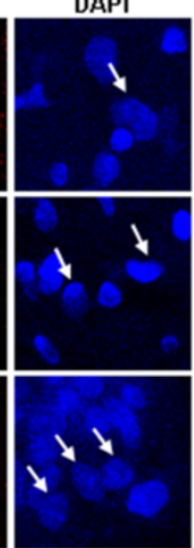

Merge

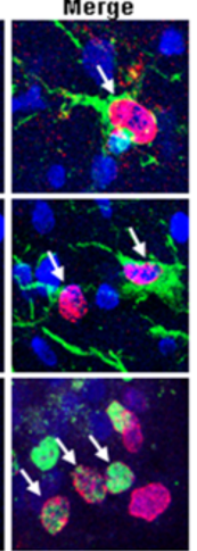

C
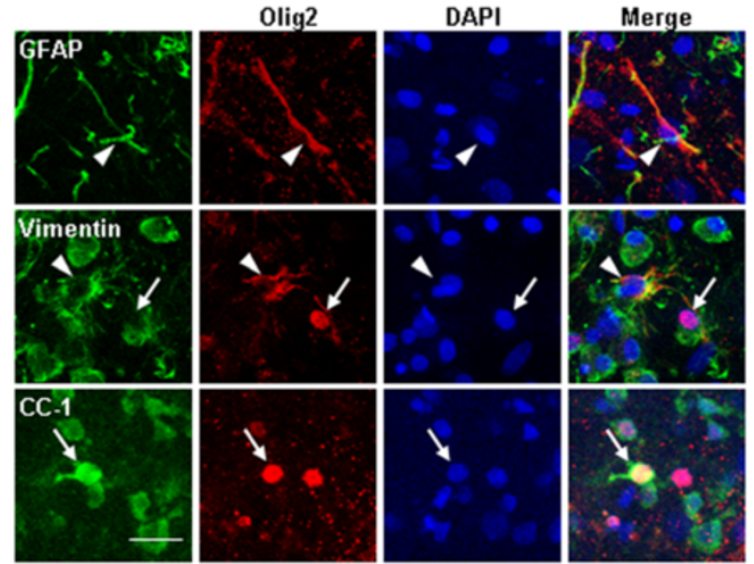

Figure 4 Ki-67 immunoreactivity was found in astrocytes and oligodendrocytes in LPS-injected SNpc. (A) Brain sections were prepared at the indicated times after LPS-, and PBS-injection and stained with antibodies specific for Ki-67. Lower panels are higher magnification of boxed areas in upper panels. In intact contralateral (contra) sides and sections from PBS-injected brains, some Ki67 ${ }^{+}$cells were detectable (black arrows). Dotted lines at 3 and $14 \mathrm{~d}$ show areas where the number of Ki67 ${ }^{+}$cells dramatically increased (whiter arrows). Asterisks $\left(^{*}\right)$ indicate injection sites. (B) Sections obtained at 3 d were double-labeled with combinations of Ki-67/GFAP, Ki-67Nimentin, and Ki67/Olig2 antibodies. Nuclei were labeled with DAPI. Arrows indicate cells co-labeled with Ki67 and each cellular marker. (C) Sections obtained at $7 \mathrm{~d}$ were double-labeled with combinations of Olig2/Nimentin and Olig2/CC-1 antibodies. Arrowheads and arrows indicate cells where Olig2 was found in the cytosol and nuclei, respectively. Scale bars, $200 \mu \mathrm{m}$ (upper panels in A), $50 \mu \mathrm{m}$ (lower panels in A), and $20 \mu \mathrm{m}(\mathbf{B}, \mathbf{C})$.

that monocytes may contribute to the recovery of impaired astrocytes in LPS-injected SNpc.

\section{Possible spatial and temporal correlation between} astrocytes and monocytes cells in the injured brain Since recovery of the damaged microenvironment was detected in the damaged core filled with monocytes, we further examined whether correlation between repair of astrocytes and infiltration of monocytes in the injured brain. In results, we observed a correlation between the distribution of round monocytes and astrocytes: astrocytes expanded their territory as the area occupied by round Iba- $1^{+} / \mathrm{CD} 45^{+}$cells decreased in a time-dependent manner (dotted lines in Figure 8A). In addition, astrocytes protruded their processes toward the damage core filled with monocytes at $7 \mathrm{~d}$ (arrows in Figure 8B, C). Furthermore,
Vimentin, which positively regulates migration of cells including astrocytes [29,30], was detectable in the protruded astrocyte processes near the damage core (arrows in Figure 8C, D), but not in astrocytes far from monocytes (arrowheads in Figure 8D).

Next, we examined whether monocytes could encourage migration of astrocytes in culture. We measured migration ability of astrocytes using the PDMS device (Figure 9A). Astrocytes (Ast) and monocytes (Mo) were plated in each side of the groove. At $7 \mathrm{~d}$ after plating, astrocytes migrated toward monocytes when the direction of convective flow was from monocytes to astrocytes (Figure 9B left panel) but not when the direction was from astrocytes to monocytes (Figure 9B right panel). In addition, astrocytes did not move toward dead monocytes or toward media alone (data not shown). Taken together, 


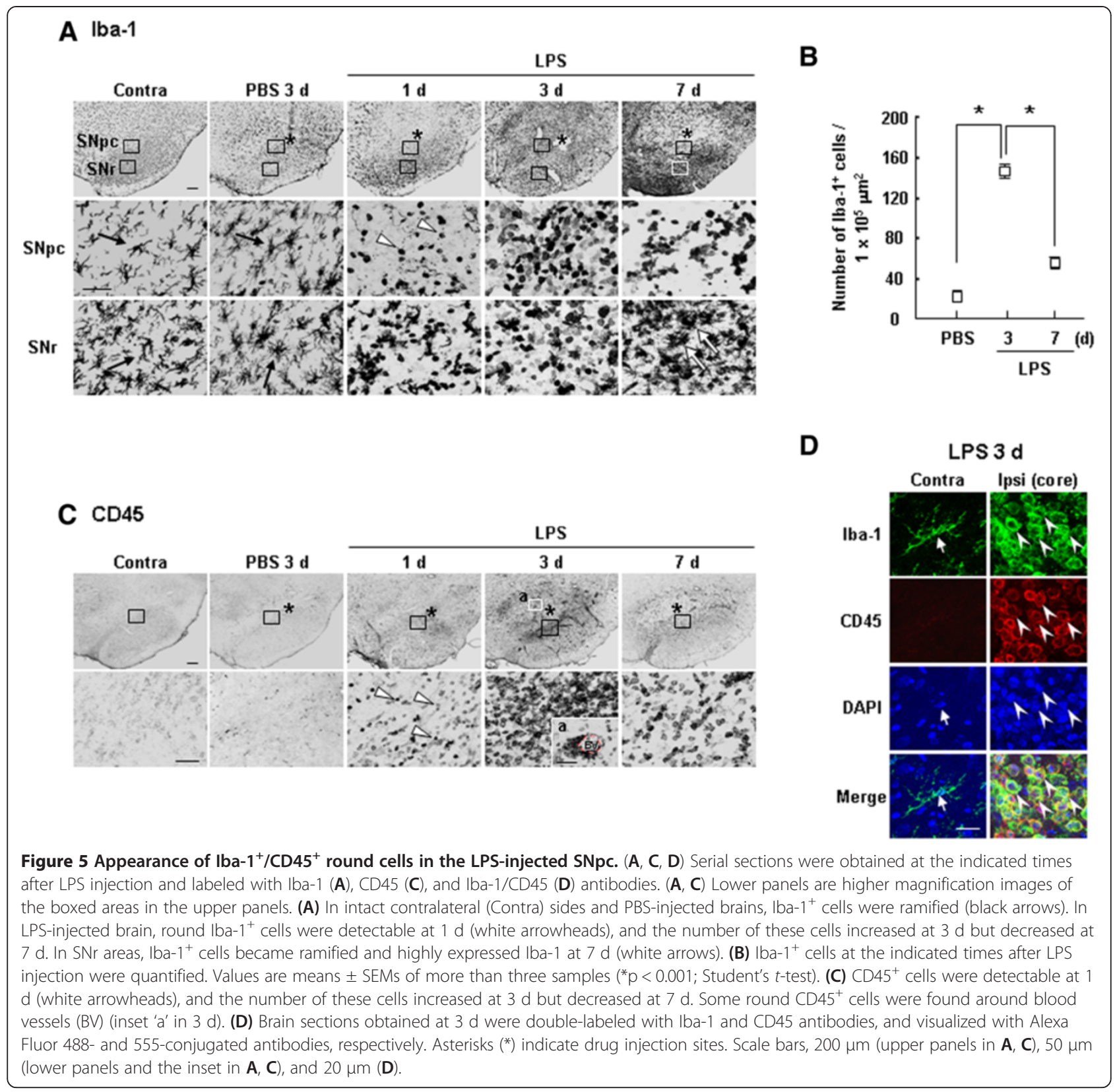

these results suggest that monocytes in brain inflammation may contribute to recovery of damaged astrocytes by promoting astrocyte migration.

\section{Discussion}

The results in this study showed that 1) astrocytes, oligodendrocytes, myelin, and endothelial cells recovered in the injured brain; 2) the recovery of these cells and myelin occurred after infiltration of Iba- $1^{+} / \mathrm{CD} 45^{+}$monocytes into injury sites; 3 ) $\mathrm{Iba}-1^{+} / \mathrm{CD} 45^{+}$monocytes expressed repair-related inflammatory mediators, but not cytotoxic proinflammatory mediators; and 4) in vitro, monocytes secreted soluble factor(s) that recruited astrocytes toward them. On the basis of these findings, we suggest that monocytes may function to repair the injured brain.

Many studies on cultured microglia have reported that brain inflammation is neurotoxic. However, brain inflammation in vivo is quite different from the inflammation associated with microglia in culture [12-15,31]. Simply, in the brain, several types of cells including microglia, astrocytes, neurons, and blood inflammatory cells, both positively and negatively contribute to inflammation. Microglia continuously survey brain damage, isolate damaged areas [14,32], and recruit monocytes [33]. Astrocytes and/or neurons inhibit microglial activation [31,34-37] 
Table 1 Primary antibodies used to detect microglia/ monocytes

\begin{tabular}{llc}
\hline Name & Detectable cell types & References \\
\hline CD11b & Brain microglia & {$[21]$} \\
\cline { 2 - 2 } & Monocytes/macrophages & \\
\hline CD45 & Monocytes (CD45 $\left.^{\text {high }}\right)$ & Microglia (CD45 \\
& Brain microglia $_{\text {Iba-1 }}$ & \\
\cline { 2 - 3 } & Monocytes/macrophages & \\
\hline
\end{tabular}

and recruit monocytes [38]. Neutrophils produce cytotoxic inflammatory mediators in the brain $[12,17]$. However, the roles of monocytes in the brain have not been clearly defined. Since monocytes/macrophages can be differentially activated (cytotoxic/classical vs. repair/alternative activation) depending on the stimuli, their roles also differ according to the activation conditions $[7,9]$. The results presented here showed that monocytes in the LPS-injected brain exhibited repair-promoting rather than neurotoxic phenotypes. In microarray, RT-PCR, and immunohistochemistry analyses, repair/resolutionrelated genes/proteins such as phagocytic activation markers were highly expressed in the LPS-injected brain during the period when monocytes appeared, whereas cytotoxic proinflammatory mediators were barely expressed (Figures 6, 7). Phagocytosis is an important process for the repair/regeneration of damaged tissue because damaged cells and debris may act as detrimental factors that lead to further injury or hinder regeneration [10]. In a multiple sclerosis animal model, stimulation of phagocytosis was shown to increase clearance of tissue debris, limit further destruction, and facilitate repair [39].

The question arising from the above considerations is how monocytes have a repair function instead of a
A Pro-inflammatory response-related genes
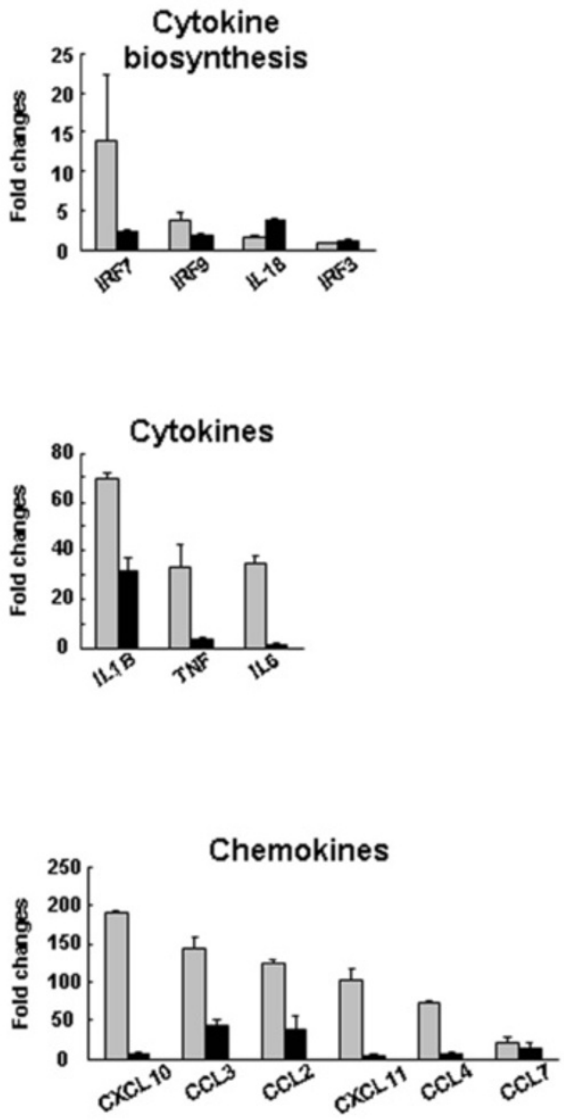

\section{B Repair/resoultion-related genes}
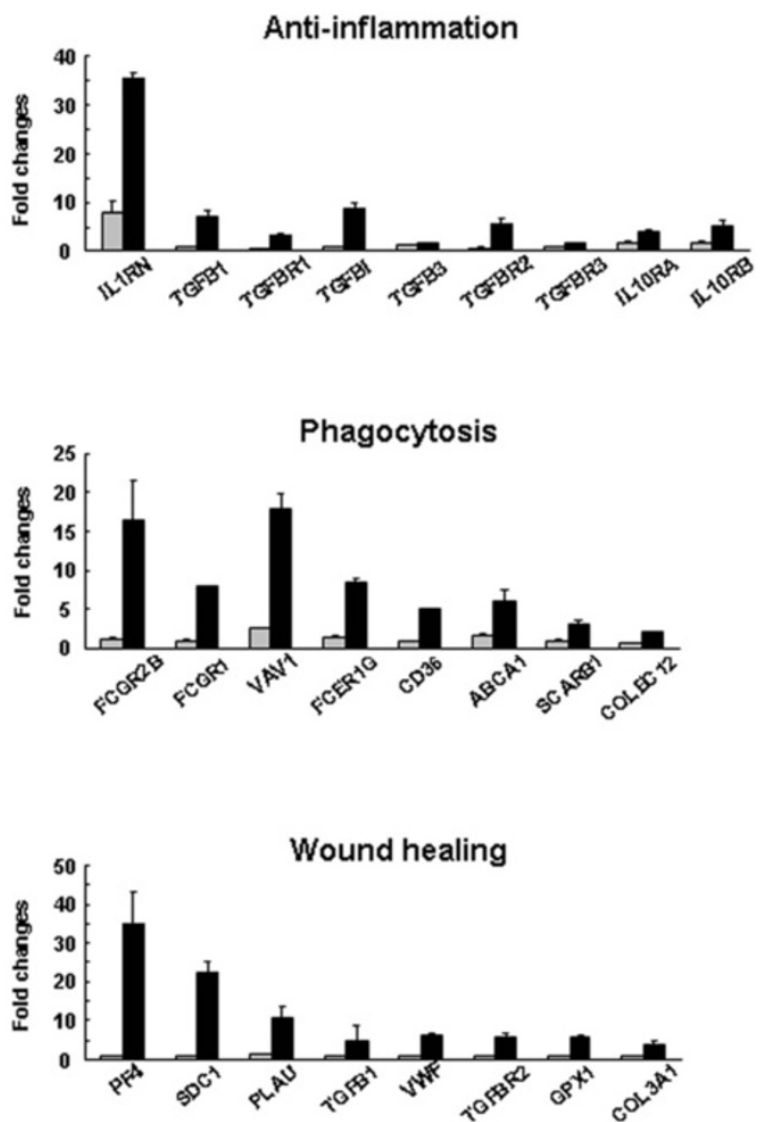

Figure 6 Microarray analysis of mRNA expression in the LPS-injected SNpc. mRNA expression profiles were compared in intact, and $3 \mathrm{~h}$ and $3 \mathrm{~d}$ after LPS-injected brain. For each microarray sample, brain tissue blocks $(2 \times 2 \times 2 \mathrm{~mm})$ were obtained from four animals, and total RNA was extracted as described in "Materials and Methods". Relative mRNA levels of proinflammatory response-related genes (A) and repair/resolutionrelated genes (B) at $6 \mathrm{~h}$ and $3 \mathrm{~d}$ after LPS injection are shown as fold-changes normalized to that in the intact SNpc. Data shown are representative of two independent experiments. 
A

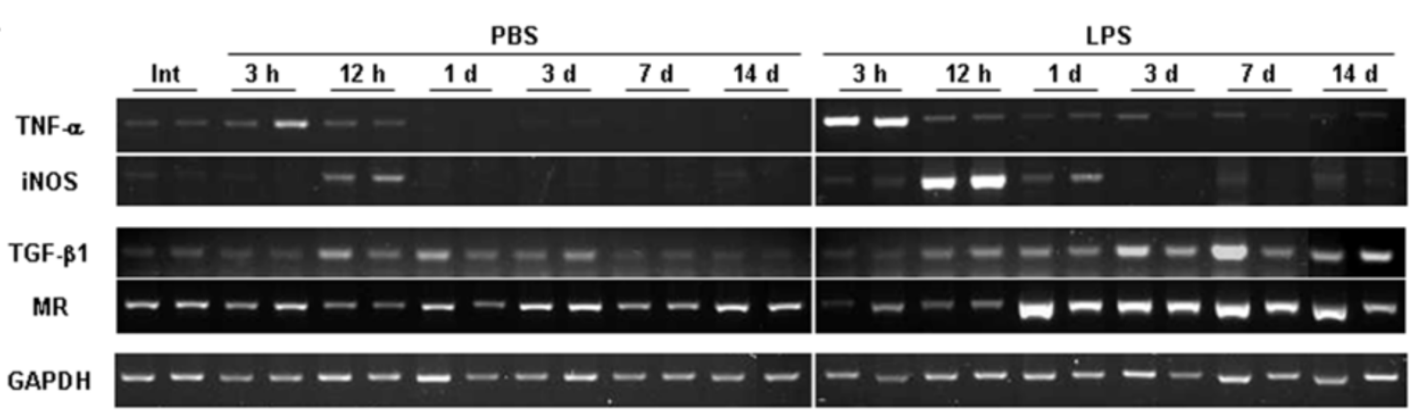

B
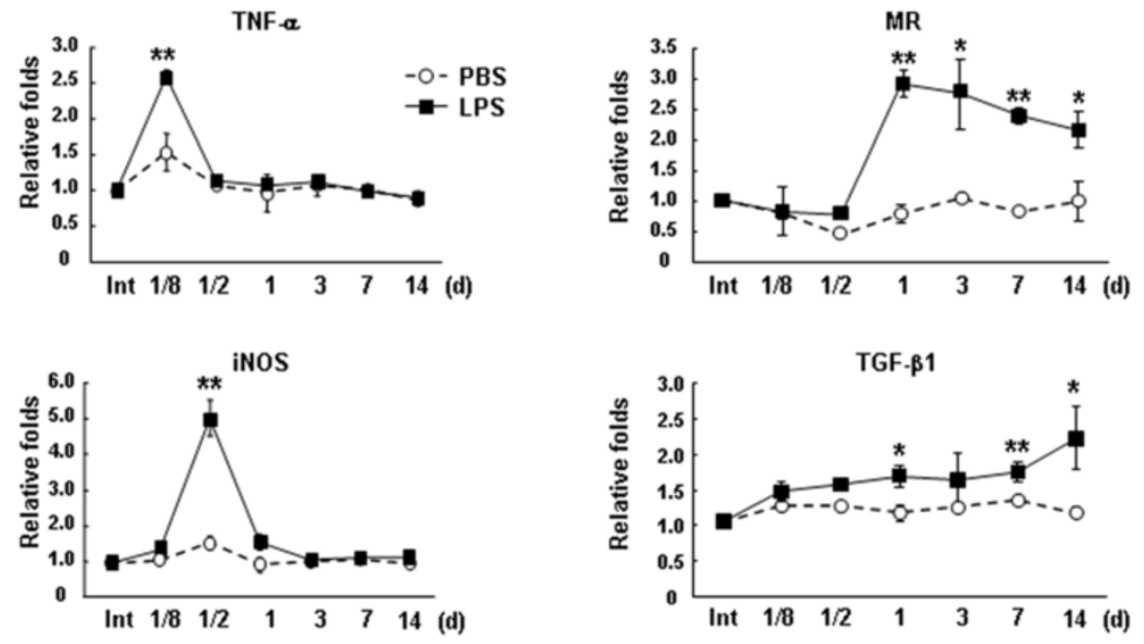

C

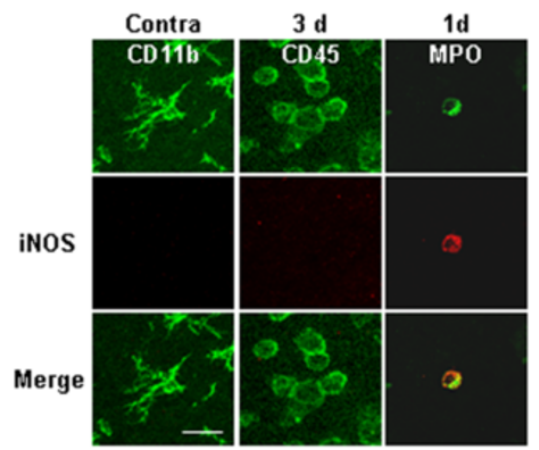

D

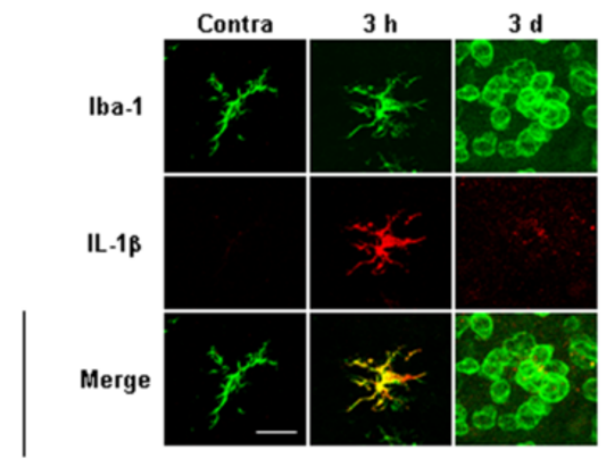

E

F
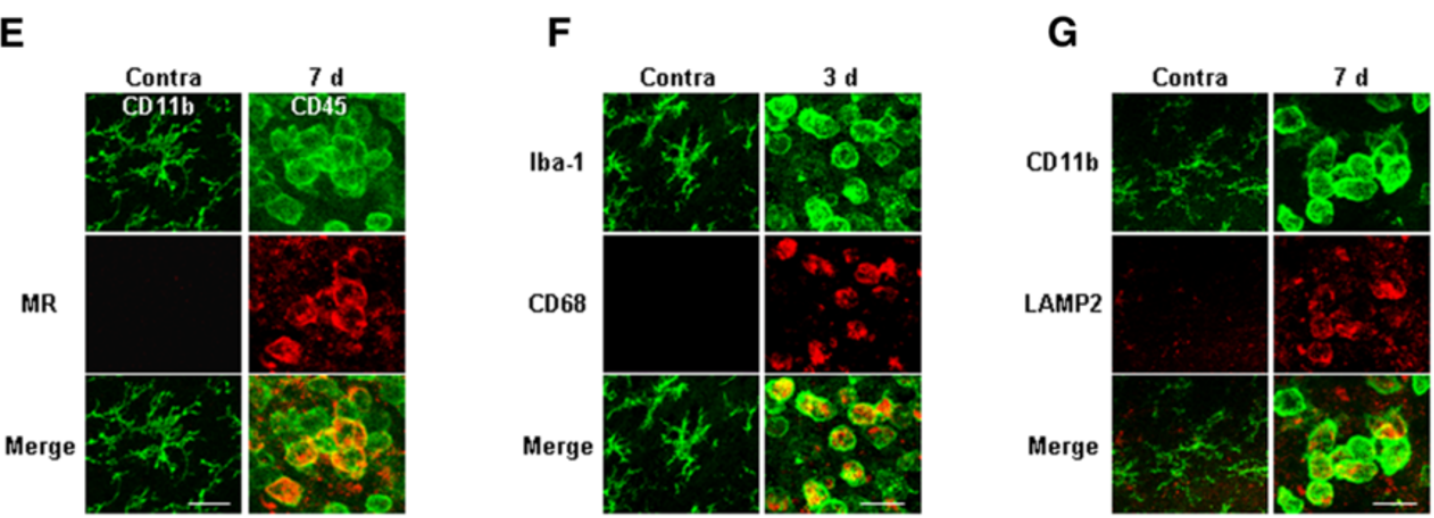

Figure 7 (See legend on next page.) 
(See figure on previous page.)

Figure $7 \mathrm{lba}-\mathbf{1}^{+} / \mathrm{CD} 45^{+}$round cells in LPS-injected SNpc were alternatively activated. (A, B) At the indicated times after LPS or PBS injection, brain tissue blocks $(2 \times 2 \times 2 \mathrm{~mm})$ were obtained, and the levels of TNF- $\alpha$, iNOS, TGF- $\beta$, and MR mRNA were analyzed by RT-PCR (A). Band intensities in (A) were analyzed and plotted (B). Intact (Int) SNpc was used as a control. (C-G) Sections were obtained at the indicated times after LPS injection and labeled with combinations of markers of microglia/monocytes (CD11b, CD45, Iba-1), neutrophils (MPO, myeloperoxidase), proinflammatory mediators (iNOS and IL-1 beta), and alternative activation and phagocytosis (MR, CD68, and LAMP2). iNOS was detected in neutrophils and IL-1 beta in ramified cells, respectively. All of MR, CD68, and LAMP2 were detected in round cells but not in ramified cells. Values in (B) are means \pm SEMs of more than three samples (* $p<0.05 ;{ }^{*}, p<0.001$ for PBS vs. LPS; Student's $t$-test). Data shown in $(\mathbf{A}$ and $\mathbf{C}$-G) are representative of more than three samples. Intact SN region (Int) and PBS injection were used as controls. Scale bars, $20 \mu \mathrm{m}$ (C-G).

neurotoxic function in the LPS-injected brain. There is a remote possibility that monocytes are activated by LPS since cerebrospinal fluid is exchanged about 11 times daily to maintain homeostasis of the brain in the adult rat brain [40]. Monocytes may be alternatively activated by phagocytosis of apoptotic cells. It has been reported that phagocytosis alters the phenotypes of monocytes from a proinflammatory to an anti-inflammatory phenotype [41]. Another possibility is that neutrophils that enter the brain prior to monocytes may induce alternative activation because neutrophils express IL-4, a strong inducer of alternative activation $[6,12,42]$.
Next, we examined the issue of how astrocytes, oligodendrocytes, myelin, endothelial cells, and neurites reappeared in damaged areas. We detected $\mathrm{Ki}-67^{+}$proliferating cells in the injured area, and these cells were merged with GFAP, Vimentin, and Olig2 (Figure 4), suggesting that astrocytes and oligodendrocytes proliferate and fill the damaged area. Interestingly, Olig2 immunoreactivity was located in the cytosol of $\mathrm{GFAP}^{+} /$Vimentin $^{+}$astrocytes and in the nuclei of $\mathrm{CC}-1^{+}$oligodendrocytes (Figure $4 \mathrm{C}$ ). It has been reported that Olig2 is expressed in progenitor cells of oligodendrocytes and astrocytes, as well as in reactive astrocytes in the injured brain $[19,20]$. As we also showed in Figure 4C,

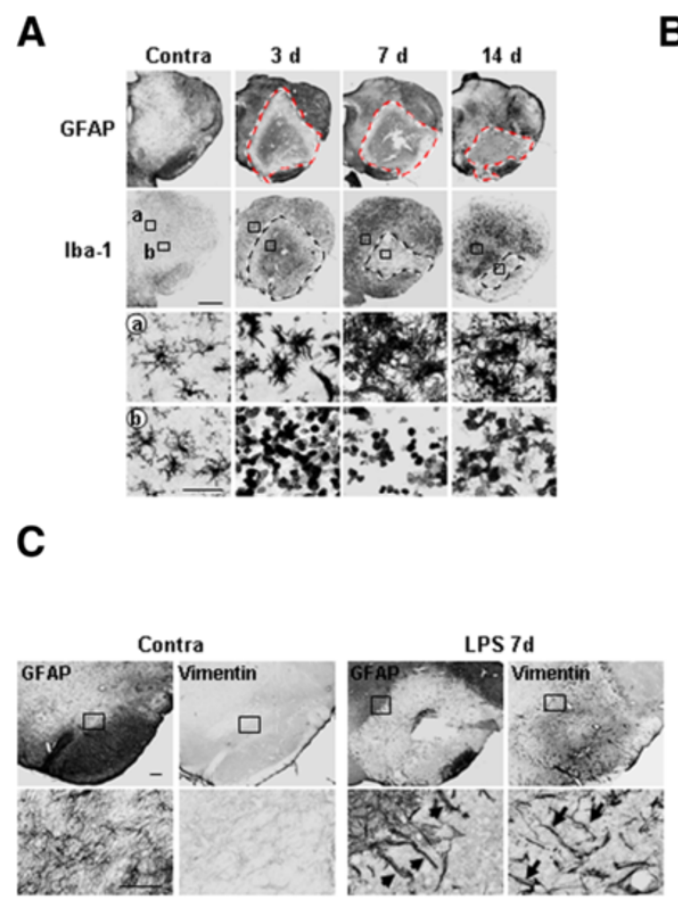

B

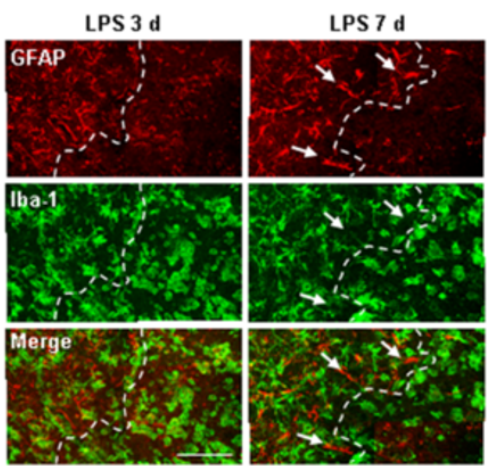

D

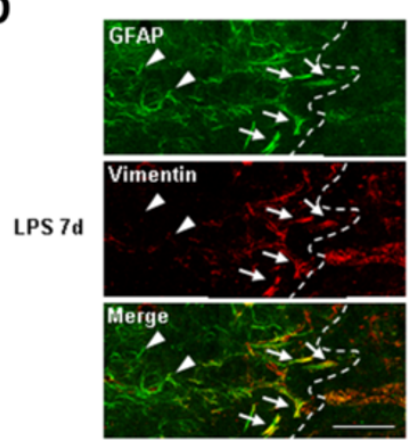

Figure 8 Possible spatial and temporal correlation between astrocytes and round lba- $\mathbf{1}^{+}$cells in the injured brain. Brain sections ( $\left.30 \mu \mathrm{m}\right)$ were obtained at the indicated times after LPS injection. (A, C) Immediately adjacent serial sections were stained with GFAP, Iba-1, and Vimentin antibodies, respectively. Lower panels are higher magnification of boxed areas in upper panels. (B, D) Sections were double-labeled with GFAP/ Iba-1 (B) or GFAPNimentin (D). Arrows indicate astrocyte processes protruded towards monocytes (B, C). Arrows and arrowheads indicate Vimentin $^{+}$astrocytes near monocytes and Vimentin astrocytes far from monocytes, respectively (D). Dotted lines in $(\mathbf{A}, \mathbf{B}$, and $\mathbf{D})$ indicate the borders where $\mathrm{GFAP}^{+}$astrocytes were absent and/or Iba- $1^{+}$round monocytes were present. Data shown are representative of at least three independent experiments. In each experiment, three or more animals were used for each time point. Scale bars, 1 mm (A), 200 Hm (upper panels in $\mathbf{C}), 100 \mu \mathrm{m}$ (B, lower panels in $\mathbf{C}$, and $\mathbf{D}), 50 \mu \mathrm{m}$ (lower panels in $\mathbf{A}$ ). 


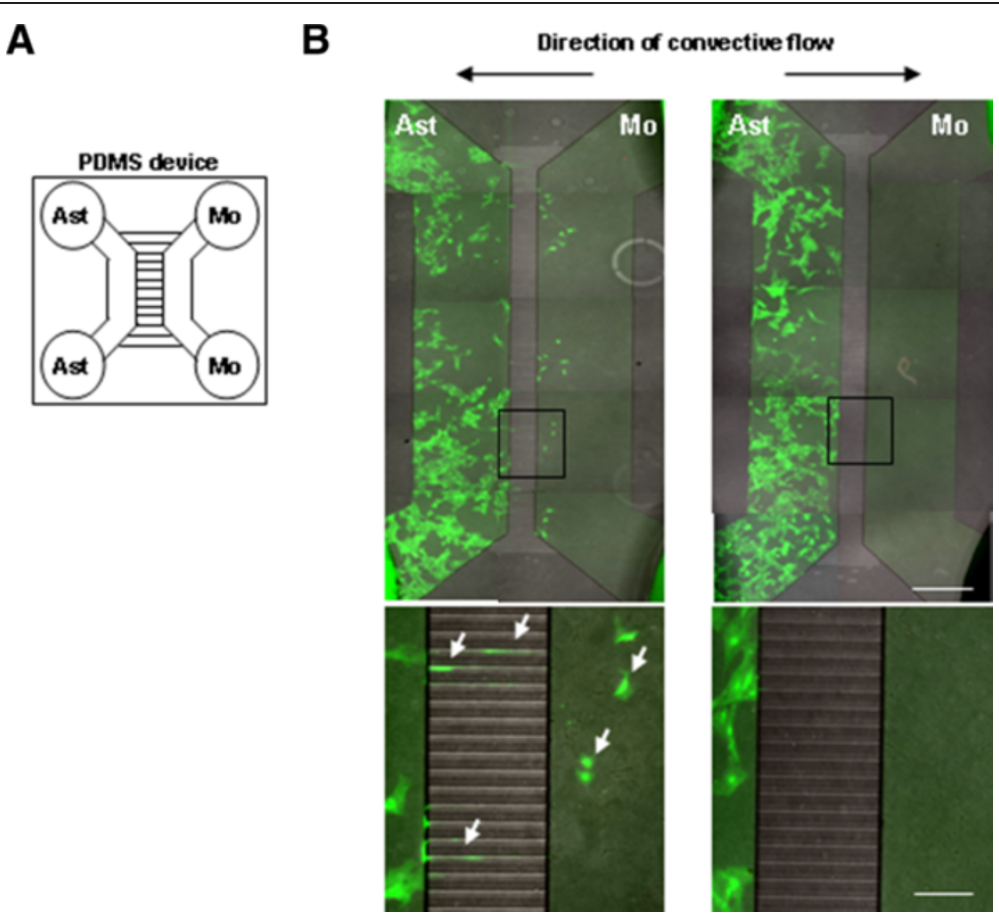

Figure 9 Monocytes facilitate astrocyte migration. Astrocytes and monocytes were co-cultured in the each compartment of PDMS devices (A) as described in "Materials and Methods". (B) At $7 \mathrm{~d}$ after co-culture, astrocytes were visualized with calcein AM. Convective flow was generated by the difference in media volumes ( 250 vs. $300 \mu \mathrm{l}$ ) in the compartments in PDMS. The volume difference was maintained to day 7. Astrocytes migrated toward monocytes through the groove only when the convective flow was from monocytes to astrocytes (white arrows in B, left panel). The lower panels in (B) represent higher magnification of the indicated areas in the upper panels. Bars $200 \mu \mathrm{m}$ (B upper panel); $50 \mu \mathrm{m}$ (B lower panel).

it has been reported that Olig2 is located in the cytosol and nuclei of cells that are destined to become astrocytes and oligodendrocytes, respectively [43,44]. Therefore, newly generated $\mathrm{Ki}_{6} 7^{+} / \mathrm{Olig} 2^{+}$progenitors may replenish astrocytes and oligodendrocytes in the injured brain. It has been reported that monocytes express several chemokines, including IL-8, IP-10, CCL1, CCL2 (MCP-1), and CCL4 $[45,46]$. Monocytes also produce platelet-derived growth factor (PDGF), transforming growth factor beta (TGF- $\beta$ ), and hepatocyte growth factor (HGF) [47-49]. Therefore, monocytes may recruit and/or promote the proliferation of astrocytes and oligodendrocytes, and induce neurite outgrowth. These findings suggest that brain inflammation plays a role in repairing damaged brain tissue. Thus, we speculate that impairment of the repair function of inflammation due to aging or genetic mutations may result in delayed recovery from damage and neurodegeneration. In our microarray analysis, mRNA expression of several genes related to cell proliferation/migration and neurogenesis was upregulated at around the times when monocytes appeared in the brain (data not shown). Furthermore, we observed that, in culture, monocytes promote astrocyte migration toward them (Figure 9), suggesting that monocytes in the LPS-injected brain may attract astrocytes toward damaged areas for recovery. We expected that the recovery of oligodendrocytes might be similar to that of $\mathrm{GFAP}^{+}$astrocytes, since they come to occupy the same microenvironment. In addition, astrocytes may contribute to the recovery of endothelial cells and neurite outgrowths since astrocytes also express neurotrophic factors and growth factors [50,51]. Taken together, these observations suggest that monocytes may assist in regeneration of the brain microenvironment in the injured brain.

\section{Conclusion}

In the present study, impaired astrocytes, endothelial cells, and neurites were recovered, and myelination occurred, after monocytes had filled the lesion sites. We thus speculate that brain inflammation mediated by monocytes serves to repair damage in the injured brain. Our results highlight the physiological importance of brain inflammation in enhancing beneficial effects while minimizing harm.

\section{Materials and methods}

\section{Ethics statement}

All experiments were performed in accordance with the approved animal protocols and guidelines established by the Ajou University School of Medicine Ethics Review Committee, and all animal work was approved by the 
Ethical Committee for Animal Research of Ajou University (Amc-28).

\section{Stereotaxic surgery and drug injection}

Male Sprague-Dawley rats (230-250 g, 7 weeks old) were anesthetized by ketamine $(40-80 \mathrm{mg} / \mathrm{kg})$ and xylazine $(5-10 \mathrm{mg} / \mathrm{kg})$, and positioned in a stereotaxic apparatus (David Kopf Instruments, Tujunga, CA, USA). LPS (5 $\mu \mathrm{g}$ in $2 \mu \mathrm{l}$ sterile PBS; Sigma, St. Louis, MO, USA) was unilaterally administered into the right $\mathrm{SNpc}$ (AP, $-5.3 \mathrm{~mm}$; ML, $-2.3 \mathrm{~mm}$; DV, $-7.6 \mathrm{~mm}$ from the bregma), according to the atlas of Paxinos and Watson [52]. All animals were injected using a Hamilton syringe equipped with a 30-gauge blunt needle and attached to a syringe pump (KD Scientific, New Hope, PA, USA). LPS was infused at a rate of $0.4 \mu \mathrm{l} / \mathrm{min}$. After injection, the needle was held in place for an additional 5 min before removal.

\section{Tissue preparation}

For immunostaining, rats were anesthetized and transcardially perfused with saline solution containing $0.5 \%$ sodium nitrate and heparin $(10 \mathrm{U} / \mathrm{ml})$, followed by $4 \%$ paraformaldehyde in $0.1 \mathrm{M}$ phosphate buffer $(\mathrm{pH}$ 7.2) for tissue fixation. Brains were obtained and post-fixed overnight at $4^{\circ} \mathrm{C}$ in $4 \%$ paraformaldehyde. Fixed brains were stored at $4^{\circ} \mathrm{C}$ in a $30 \%$ sucrose solution until they sank. Six separate series of $30-\mu \mathrm{m}$ coronal brain sections $(50 \mu \mathrm{m}$ for stereological counting) were obtained using a sliding microtome (Microm, Walldorf, Germany).

For RNA preparation, rats were anesthetized and transcardially perfused with saline solution without paraformaldehyde. Brains were obtained and sliced with a Rat Brain Slicer Matrix (1.0 mm slice intervals, RBM4000C; ASI Instruments, Warren, MI, USA) and a razor blade. A slice that included the needle injection spot was selected, and tissue blocks $(2 \times 2 \times 2 \mathrm{~mm})$ just below the needle tip were collected and stored at $-70^{\circ} \mathrm{C}$ until use.

\section{Immunohistochemistry}

For 3,3'-diaminobenzidine (DAB) staining, serial sections were rinsed three times with PBS, treated with $3 \%$ $\mathrm{H}_{2} \mathrm{O}_{2}$ for $5 \mathrm{~min}$, and rinsed with PBS containing $0.2 \%$ Triton X-100 (PBST). Non-specific binding was blocked with $1 \%$ BSA in PBST. Sections were incubated overnight at room temperature with primary antibodies (Table 2). After rinsing in PBST, sections were incubated with biotinylated secondary antibodies (Vector Laboratories, Burlingame, CA, USA) for $1 \mathrm{~h}$ and the avidin/biotin system (Vector Laboratories) for $1 \mathrm{~h}$, and visualized using a DAB solution $(0.05 \% \mathrm{DAB}$ and $0.003 \%$ hydrogen peroxide in $0.1 \mathrm{M} \mathrm{PB}$ ). Sections were then mounted on gelatin-coated slides and examined under a bright-field
Table 2 Primary antibodies used in immunohistochemistry

\begin{tabular}{ccccc}
\hline Antibody & Source & Dilution & Catalogue no. & Company \\
\hline APC (CC-1) & mouse & $1: 200$ & OP80 & Calbiochem \\
\hline CD11b & mouse & $1: 200$ & MCA275G & Serotec \\
\hline CD45 & mouse & $1: 200$ & MCA43R & Serotec \\
\hline CD68 & mouse & $1: 300$ & MCA341R & Serotec \\
\hline EAAT1 & rabbit & $1: 800$ & 416 & Abcam \\
\hline GFAP & mouse & $1: 700$ & G3893 & Sigma \\
\hline Iba-1 & rabbit & $1: 1000$ & 019-19741 & Wako \\
\hline Ki-67 & rabbit & $1: 200$ & AB9260 & Chemicon \\
\hline Kir4.1 & rabbit & $1: 800$ & apc-035 & Alomone \\
\hline LAMP2 & rabbit & $1: 200$ & L0668 & Sigma \\
\hline MAP2 & mouse & $1: 1000$ & M4403 & Sigma \\
\hline MR & rabbit & $1: 200$ & ab64693 & Abcam \\
\hline Olig2 & rabbit & $1: 200$ & OB-905 & IBL \\
\hline SMI 71 & mouse & $1: 500$ & SMl-71R & Sternberger \\
& & & & Monoclonals \\
\hline S100ß & rabbit & $1: 800$ & 37 & Swant \\
\hline TH & rabbit & $1: 1000$ & P40101 & Pel-Freeze \\
\hline Vimentin & mouse & $1: 200$ & MAB3400 & Chemicon \\
\hline & & & &
\end{tabular}

microscope (Olympus Optical, BX51, Tokyo, Japan). Bright-field images were obtained using PictureFrame Application 2.3 software. For immunofluorescence staining, sections were washed twice in PBS, treated with $1 \%$ BSA, and incubated with combinations of primary antibodies. For double-labeling, resident microglia and monocytes were stained for Iba-1, CD11b, or CD45 depending on the sources of antibodies against other proteins (Table 1). For visualization, Alexa Fluor 488or Alexa Fluor 555-conjugated secondary antibodies (Invitrogen, Eugene, OR, USA) were used. DAPI (Vector Laboratories) was used to detect nuclei. Sections were analyzed under a confocal microscope (LSM 510, Carl Zeiss, Jena, Germany) with $40 \times$ water- and $63 \times$ oilimmersion objectives at $20^{\circ} \mathrm{C}$. Images were captured using Confocal software (LSM Image Browser).

\section{Reverse transcriptase-polymerase chain reaction (RT-PCR)}

Total RNA was isolated using an easy-BLUE RNA Extraction Kit (iNtRON, Sungnam, Korea), and cDNA was prepared using Reverse Transcription Master Premix (ElpisBio, Daejeon, Korea), according to the manufacturers' instructions. Approximately $100 \mathrm{ng}$ cDNA was analyzed. The specific primers for TNF- $\alpha$, iNOS, TGF- $\beta$, MR, and GAPDH used in RT-PCR are shown in Table 3. RT-PCR products were verified by electrophoresis on $1.5 \%$ agarose gels with GelRed (Biotium, Hayward, CA, USA) staining. GAPDH was used as a reference. Band intensities were analyzed using Quantity One 1-D analysis software, v 4.6.5 (Bio-Rad Laboratories, Inc., Hercules, CA, USA). 
Table 3 Primer sequences for RT-PCR

\begin{tabular}{|c|c|}
\hline Gene & Sequence $\left(5^{\prime}-3^{\prime}\right)$ \\
\hline \multirow[t]{2}{*}{ TNF-a } & F: GTAGCCCACGTCGTAGCAAA \\
\hline & R: CCCTTCTCCAGCTGGGAGAC \\
\hline \multirow[t]{2}{*}{ iNOS } & F: GCAGAATGTGACCATCATGG \\
\hline & R: ACAACCTTGGTGTTGAAGGC \\
\hline \multirow[t]{2}{*}{ TGF- $\beta$} & F: GAGAGCCCTGGATACCAACTACTG \\
\hline & R: GTGTGTCCAGGCTCCAAATGTAG \\
\hline \multirow[t]{2}{*}{$\mathrm{MR}$} & F: GTAGTTCTATCTTCATCTTC \\
\hline & R: AATATAAGACAGTCACATTA \\
\hline \multirow[t]{2}{*}{ GAPDH } & F: TCCCTCAAGATTGTCAGCAA \\
\hline & R: AGATCCACAACGGATACATT \\
\hline
\end{tabular}

$F$ Forward primer, $R$ Reverse primer.

\section{Microarray analysis}

\section{Sample preparation and labeling}

Microarray experiments were performed in duplicate. For each sample, total RNA was extracted from tissue blocks $(2 \times 2 \times 2 \mathrm{~mm})$ obtained from four LPS-injected and uninjected rat brains using RNeasy mini kits (Qiagen GmbH, Hilden, Germany). Quantity and quality of RNA were assayed by UV spectrometry and RNA gel electrophoresis. RNA was labeled and hybridized to a GeneChip according to Standard Affymetrix Protocols (GeneChip Whole Transcript Sense Target Labeling Assay Manual, Version 4; Affymetrix, Santa Clara, CA). Affymetrix GeneChip Rat Gene 1.0 ST Arrays were used in this study. Each reaction involving a single GeneChip hybridization was initiated with 200 ng RNA. cDNA and cRNA were generated using a GeneChip WT cDNA Synthesis and Amplification Kit (900673, Affymetrix); cRNA cleanup was performed using a GeneChip IVT cRNA Cleanup Kit (900547, Affymetrix). After the second cDNA synthesis, cRNA was hydrolyzed by RNase $\mathrm{H}$ treatment, and biotin-labeled sense strand DNA fragments were generated using a GeneChip WT Terminal Labeling Kit (900671, Affymetrix).

\section{Hybridization and scanning}

Biotin-labeled DNA fragments (target) or controls in a hybridization cocktail were hybridized to the GeneChip array by incubating for $16 \mathrm{~h}$ in a GeneChip Hybridization Oven 640. Immediately following hybridization, the array was washed and stained with a streptavidin-phycoerythrin conjugate on the GeneChip Fluidics Station 450 using an automated protocol, followed by scanning on a GeneChip Scanner 3000 (7G). The GeneChip Hybridization, Wash, and Stain Kit (900720, Affymetrix) was used in this procedure.

\section{Data measurement and analysis}

An Affymetrix GeneChip scanner operated by GeneChip Operating Software (GCOS ver1.4; Affymetrix) was used to generate original array images. The average difference for each probe set (a measure of the relative abundance of a transcript) and signals and detection calls (i.e., present or absent) were computed using GCOS. Data were analyzed using Silicon Genetics Genespring 10.1 Software.

\section{Eriochrome cyanine RC staining}

Myelin was visualized with Eriochrome Cyanine RC (ECRC; Sigma). Brain sections were mounted on slides and air-dried overnight at room temperature. After dehydration and rehydration in graded ethanol solutions, sections were stained with ECRC solution $(0.2 \%$ in $0.5 \%$ $\mathrm{H}_{2} \mathrm{SO}_{4}$ ) for $10 \mathrm{~min}$, rinsed in running tap water, placed in $1 \% \mathrm{NH}_{4} \mathrm{OH}$ for $30 \mathrm{~s}$, and rinsed in distilled water. After dehydration, sections were treated with xylene and mounted using Permount (Fisher Scientific Co., Morris Plains, NJ, USA).

\section{Measurement of damaged areas}

Damaged areas were measured by staining every sixth brain section of the whole midbrain (AP, -4.3 to $-6.5 \mathrm{~mm}$ from the bregma) with antibodies for specific markers of astrocytes (GFAP, S100 $\beta$, EAAT1, and Kir4.1), endothelial cells (SMI 71), and neurites (MAP2). Myelin was stained with ECRC. Specific marker-negative areas in serial sections were measured on $4 \times$-magnified images using Axiovision image-analysis software (version 4.7.2; Zeiss) and summed as shown in Additional file 3: Figure S3.

\section{Cell culture}

Primary astrocytes were cultured from the cerebral cortices of 1-day-old Sprague-Dawley rats, as described previously $[53,54]$. In brief, cortices were triturated in MEM (Sigma) containing 10\% FBS (HyClone, Logan, UT, USA), plated in $75 \mathrm{~cm}^{2}$ T-flasks (0.5 hemisphere/ flask), and incubated for 2-3 weeks. Microglia were removed from flasks by mild shaking, and astrocytes were cultured in serum-free MEM for 2-3 d. Astrocytes were harvested with $0.1 \%$ trypsin, plated, and cultured in MEM containing 10\% FBS before use. Purity of astrocytes (>95\%) was confirmed using GFAP antibodies.

Rat blood monocytes were isolated as described previously [55]. Briefly, blood was obtained by cardiac puncture and mixed with $2.5 \%$ dextran in PBS for $1 \mathrm{~h}$ at RT. The plasma layer was centrifuged at $300 \times g$ for $12 \mathrm{~min}$. To remove red blood cells (RBC), the pellet was suspended in PBS containing $0.15 \mathrm{M} \mathrm{NH} \mathrm{Nl}_{4}, 10 \mathrm{mM} \mathrm{NaHCO}$, and $0.1 \mathrm{mM}$ EDTA, and centrifuged at $350 \times g$ for $6 \mathrm{~min}$. This process was repeated twice. Pellets containing monocytes and lymphocytes were suspended in PBS and placed in 15-ml polystyrene conical tubes (BD Falcon, NJ, USA). An equal volume of Ficoll-Paque PLUS (GE Healthcare, Uppsala, Sweden) was carefully added to the bottom of cell-containing tubes so as to prevent mixing with PBS. 
After centrifugation at $450 \times g$ for $30 \mathrm{~min}$, cells between the Ficoll and PBS layers were collected, washed with PBS, suspended in HBSS containing calcium (140 mg/l), and plated in a Petri dish for $30 \mathrm{~min}$. Unattached lymphocytes were removed and adherent monocytes were collected and cultured in MEM containing 10\% FBS.

\section{Astrocyte migration assay}

Astrocyte migration was examined using a polydimethylsiloxane (PDMS) device [56] that was a gift from N. Jeon (Seoul National University). Briefly, PDMS device was comprised of two compartments. Each compartment had two reservoirs in the form of 8-mm-diameter holes, one at either end of the compartment, which served as a loading gate and medium reservoir, respectively (Figure 9A). The two holes in each compartment were connected by a main channel that was $1.5 \mathrm{~mm}$ wide, $100 \mu \mathrm{m}$ high, and $7 \mathrm{~mm}$ in length. The two compartments were connected by 100 grooves, each $10 \mu \mathrm{m}$ wide, $5 \mu \mathrm{m}$ high, and $450 \mu \mathrm{m}$ in length. Primary astrocytes $\left(3 \times 10^{4}\right.$ cells/125-150 $\mu \mathrm{l}$ for each hole) were plated in one compartment, and culture media (150 $\mu \mathrm{l}$ for each hole) was added to the other compartment. The following day, the media was removed from the media-filled compartment and then monocytes $\left(2.5 \times 10^{4}\right.$ cells/125-150 $\mu$ l for each hole) were added to the compartment. The size of the grooves was sufficiently small that cells could not pass over to the opposite compartment during loading. The volume difference $(50 \mu \mathrm{l})$ between compartments leads to convective flow from the higher volume side to the lower volume side. The difference in volume slowly decreased over time, but was still $10 \mu \mathrm{l}$ at $7 \mathrm{~d}$. Phase contrast images were taken every day and calcein AM-labeled fluorescence images were taken at $7 \mathrm{~d}$ using an AxioVision fluorescence light microscope (Zeiss Axiovert $200 \mathrm{M}$ ).

\section{Statistical analysis}

All values are expressed as means \pm SEMs. The statistical significance of differences between mean values was assessed by Student's $t$-test using the Statistical Package for Social Sciences 8.0 (SPSS Inc., Chicago, IL, USA).

\section{Additional files}

Additional file 1: Figure S1. Nissl staining showed death of neurons and glia in LPS-injected SN. (A) Brain sections $(30 \mu \mathrm{m})$ prepared at $1 \mathrm{~d}$ after PBS- and LPS-injection were stained with Nissi. (B) Higher magnification images of boxed areas in (A) showed neurons (black arrow heads) and qua (white arrows) in the contralateral (Contra) and PBSinjected (PBS) SNpc and SNr. In LPSinjected SNpc, neurons and glia disappeared GFAP levels increased in all over the midbrain in PBSinjected brain (PBS). but disappeared in LPS-injected brain (LPS). (C) Higher magnification images of boxed areas in (B) showed infiltration of polymorphonuclei-containing neutrophils (white arrow heads) in LPSinjected brain (LPS) as shown previously (Ji et al., GLIA. 2007. 55:1577). Morphology of neutrophil's nuclei are obviously different from that of glia (white arrows) and neurons (black arrow heads) in contralateral side and PBS-injected brain. Asterisks $\left(^{*}\right)$ indicate injection sites. Scale bars, 1 $\mathrm{mm}$ (upper panels in $\mathbf{A}$ and $\mathbf{B}$ ), $50 \mu \mathrm{m}$ (lower panels in $\mathbf{A}$ )

Additional file 2: Figure S2. TUNEL ${ }^{+}$signals were detected in Iba- $\mathrm{V}$ round cells in LPS-injected brain. Brain sections $(30 \mu \mathrm{m})$ were prepared at 3 $\mathrm{d}$ after LPS-injection, and stained with ba-i and TUNEL. TUNEL signals were detected in some of Iba-1' round cells (arrow heads). Scale bar, $20 \mu \mathrm{m}$.

Additional file 3: Figure S3. Measurement of GFAP astrocyte-damaged areas. (A, B) Brain sections $(30 \mu \mathrm{m})$ were prepared at the indicated times after PBS- and LPS-injection, and stained with GFAP antibodies, (A) GFAP astrocytes were found in all over the mid brain, but densities of astrocytes differ depending on regions: low in red nucleus (RN) and SNpc. but high in SNr (Intact). GFAP levels increased in all over the midbrain in PBS-injected brain (PBS). but disappeared in LPS injected brain (LPS). GFAP ${ }^{+}$astrocytes were still detectable in the surrounding area of damage core (medial geniculate, MG). Lower panels are higher magnification images of boxed areas in upper panels. Asterisks $\left(^{*}\right)$ indicate injection sites Contralateral (Contra) sides of LPS-injected animals and PBS-injected animals were used as controls (B) GFAP-negative areas (areas within dotted lines) were measured in every sixth brain section of the whole mid brain and summed Scale bar. $1 \mathrm{~mm}$ (upper panels in $\mathbf{A}$ and $\mathbf{B}$ ), $50 \mu \mathrm{m}$ (lower panels in $\mathbf{A}$ ).

\section{Competing interests}

The authors declare that they have no competing interest.

\section{Authors' contributions}

$\mathrm{HJ}$ designed the study and performed the bulk of the experiments and analyzed the data, and wrote the manuscript. KJ performed the experiments and analyzed the data, and supported to prepare manuscript. JK assisted with the animal experiments. IJ provided the materials and equipments in experiments. EJ supervised the design of study and coordination, analyzed the data, and wrote the manuscript. All authors have read and approved the final version of this manuscript.

\section{Acknowledgements}

This work was supported by a KOSEF NRL Program grant (no. 2-2008025-0) funded by the Korean government (MEST), a grant (NRF-2012R1A5A2051429) from KOSEF through the Chronic Inflammatory Disease Research Center (CIDRC) at Ajou University, and a National Research Foundation of Korea Grant (NRF-2011-355-E00087) funded by the Korean Government (Ministry of Education, Science and Technology).

\section{Author details}

${ }^{1}$ Neuroscience Graduate Program, Department of Biomedical Sciences, Ajou University School of Medicine, Suwon, Kyunggi-do 443-721, Korea. ${ }^{2}$ Department of Pharmacology, Ajou University School of Medicine, Suwon, Kyunggi-do 443-721, Korea. ${ }^{3}$ National Research Lab of Brain inflammation, Ajou University School of Medicine, Suwon, Kyunggi-do 443-721, Korea. ${ }^{4}$ Chronic Inflammatory Disease Research Center, Ajou University School of Medicine, Suwon, Kyunggi-do 443-721, Korea.

Received: 21 March 2013 Accepted: 1 May 2013

Published: 10 June 2013

\section{References}

1. De Keyser J, Mostert JP, Koch MW: Dysfunctional astrocytes as key players in the pathogenesis of central nervous system disorders. J Neurol Sci 2008, 267(1-2):3-16.

2. Serhan CN, Savill J: Resolution of inflammation: the beginning programs the end. Nat Immunol 2005, 6(12):1191-1197.

3. Stavitsky $A B$ : The innate immune response to infection, toxins and trauma evolved into networks of interactive, defensive, reparative, regulatory, injurious and pathogenic pathways. Mol Immunol 2007, 44(11):2787-2799.

4. Oswald IP, Wynn TA, Sher A, James SL: Interleukin 10 inhibits macrophage microbicidal activity by blocking the endogenous production of tumor necrosis factor alpha required as a costimulatory factor for interferon gamma-induced activation. Proc Natl Acad Sci U S A 1992, 89(18):8676-8680. 
5. Wynn TA, Oswald IP, Eltoum IA, Caspar P, Lowenstein CJ, Lewis FA, James $\mathrm{SL}$, Sher A: Elevated expression of Th1 cytokines and nitric oxide synthase in the lungs of vaccinated mice after challenge infection with Schistosoma mansoni. J Immunol 1994, 153(11):5200-5209.

6. Stein M, Keshav S, Harris N, Gordon S: Interleukin 4 potently enhances murine macrophage mannose receptor activity: a marker of alternative immunologic macrophage activation. J exper med 1992, 176(1):287-292.

7. Gordon S: Alternative activation of macrophages. Nat Rev Immunol 2003, 3(1):23-35.

8. van Amerongen MJ, Harmsen MC, van Rooijen N, Petersen AH, van Luyn MJ. Macrophage depletion impairs wound healing and increases left ventricular remodeling after myocardial injury in mice. Am J Pathol 2007, 170(3):818-829.

9. Mosser DM, Edwards JP: Exploring the full spectrum of macrophage activation. Nat Rev Immunol 2008, 8(12):958-969.

10. Leibovich SJ, Ross R: The role of the macrophage in wound repair. A study with hydrocortisone and antimacrophage serum. Am J Pathol 1975, 78(1):71-100

11. Kotter MR, Zhao C, van Rooijen N, Franklin RJ: Macrophage-depletion induced impairment of experimental CNS remyelination is associated with a reduced oligodendrocyte progenitor cell response and altered growth factor expression. Neurobiol Dis 2005, 18(1):166-175.

12. Ji KA, Yang MS, Jeong HK, Min KJ, Kang SH, Jou I, Joe EH: Resident microglia die and infiltrated neutrophils and monocytes become major inflammatory cells in lipopolysaccharide-injected brain. Glia 2007, 55(15):1577-1588.

13. Ji KA, Eu MY, Kang SH, Gwag BJ, Jou I, Joe EH: Differential neutrophil infiltration contributes to regional differences in brain inflammation in the substantia nigra pars compacta and cortex. Glia 2008, 56(10):1039-1047.

14. Jeong HK, Ji KM, Kim B, Kim J, Jou I, Joe EH: Inflammatory responses are not sufficient to cause delayed neuronal death in ATP-induced acute brain injury. PLoS One 2010, 5(10):e13756.

15. Min KJ, Jeong HK, Kim B, Hwang DH, Shin HY, Nguyen AT, Kim JH, Jou I, Kim BG, Joe EH: Spatial and temporal correlation in progressive degeneration of neurons and astrocytes in contusion-induced spinal cord injury. I neuroinflammation 2012, 9(1):100.

16. Hallenbeck JM, Dutka AJ, Tanishima T, Kochanek PM, Kumaroo KK, Thompson CB, Obrenovitch TP, Contreras TJ: Polymorphonuclear leukocyte accumulation in brain regions with low blood flow during the early postischemic period. Stroke j cereb circulat 1986, 17(2):246-253.

17. Matsumoto $H$, Kumon $Y$, Watanabe H, Ohnishi T, Shudou M, li C, Takahashi H, Imai Y, Tanaka J: Antibodies to CD11b, CD68, and lectin label neutrophils rather than microglia in traumatic and ischemic brain lesions. J Neurosci Res 2007, 85(5):994-1009.

18. De Pablos RM, Herrera AJ, Villaran RF, Cano J, Machado A: Dopaminedependent neurotoxicity of lipopolysaccharide in substantia nigra. FASEB j off publ Federat Am Soc Exper Biol 2005, 19(3):407-409.

19. Marshall CA, Novitch BG, Goldman JE: Olig2 directs astrocyte and oligodendrocyte formation in postnatal subventricular zone cells. I neurosci offi j Soc Neurosci 2005, 25(32):7289-7298.

20. Chen Y, Miles DK, Hoang T, Shi J, Hurlock E, Kernie SG, Lu QR: The basic helix-loop-helix transcription factor olig2 is critical for reactive astrocyte proliferation after cortical injury. I neurosci off j Soc Neurosci 2008, 28(43):10983-10989.

21. Akiyama H, McGeer PL: Brain microglia constitutively express beta-2 integrins. J Neuroimmunol 1990, 30(1):81-93.

22. Imai Y, Ibata I, Ito D, Ohsawa K, Kohsaka S: A novel gene iba1 in the major histocompatibility complex class III region encoding an EF hand protein expressed in a monocytic lineage. Biochem Biophys Res Commun 1996, 224(3):855-862.

23. Ito D, Imai Y, Ohsawa K, Nakajima K, Fukuuchi Y, Kohsaka S: Microgliaspecific localisation of a novel calcium binding protein, Iba1. Brain res Mol brain res 1998, 57(1):1-9.

24. Campanella M, Sciorati C, Tarozzo G, Beltramo M: Flow cytometric analysis of inflammatory cells in ischemic rat brain. Stroke j cereb circulat 2002, 33(2):586-592

25. Aderem A, Underhill DM: Mechanisms of phagocytosis in macrophages. Annu Rev Immunol 1999, 17:593-623.

26. Astarie-Dequeker C, N'Diaye EN, Le Cabec V, Rittig MG, Prandi J, Maridonneau-Parini I: The mannose receptor mediates uptake of pathogenic and nonpathogenic mycobacteria and bypasses bactericidal responses in human macrophages. Infect Immun 1999, 67(2):469-477.
27. da Silva RP, Gordon S: Phagocytosis stimulates alternative glycosylation of macrosialin (mouse CD68), a macrophage-specific endosomal protein Biochem J 1999, 338(Pt 3):687-694.

28. Huynh KK, Eskelinen EL, Scott CC, Malevanets A, Saftig P, Grinstein S: LAMP proteins are required for fusion of lysosomes with phagosomes. EMBO $J$ 2007, 26(2):313-324.

29. Ivaska J, Pallari HM, Nevo J, Eriksson JE: Novel functions of vimentin in cell adhesion, migration, and signaling. Exper cell res 2007, 313(10):2050-2062.

30. Wang K, Bekar LK, Furber K, Walz W: Vimentin-expressing proximal reactive astrocytes correlate with migration rather than proliferation following focal brain injury. Brain res 2004, 1024(1-2):193-202.

31. Yang MS, Min KJ, Joe E: Multiple mechanisms that prevent excessive brain inflammation. J Neurosci Res 2007, 85(11):2298-2305.

32. Davalos D, Grutzendler J, Yang G, Kim JV, Zuo Y, Jung S, Littman DR, Dustin ML, Gan WB: ATP mediates rapid microglial response to local brain injury in vivo. Nat Neurosci 2005, 8(6):752-758.

33. D'Mello C, Le T, Swain MG: Cerebral microglia recruit monocytes into the brain in response to tumor necrosis factoralpha signaling during peripheral organ inflammation. J neurosci off j Soc Neurosci 2009, 29(7):2089-2102.

34. Pyo H, Yang MS, Jou I, Joe EH: Wortmannin enhances lipopolysaccharideinduced inducible nitric oxide synthase expression in microglia in the presence of astrocytes in rats. Neurosci Lett 2003, 346(3):141-144

35. Mott RT, Ait-Ghezala G, Town T, Mori T, Vendrame M, Zeng J, Ehrhart J, Mullan M, Tan J: Neuronal expression of CD22: novel mechanism for inhibiting microglial proinflammatory cytokine production. Glia 2004, 46(4):369-379.

36. Min KJ, Yang MS, Kim SU, Jou I, Joe EH: Astrocytes induce hemeoxygenase- 1 expression in microglia: a feasible mechanism for preventing excessive brain inflammation. I neurosci off j Soc Neurosci 2006, 26(6):1880-1887.

37. Kim JH, Min KJ, Seol W, Jou I, Joe EH: Astrocytes in injury states rapidly produce anti-inflammatory factors and attenuate microglial inflammatory responses. J Neurochem 2010, 115(5):1161-1171.

38. Kim B, Jeong HK, Kim JH, Lee SY, Jou I, Joe EH: Uridine 5'-diphosphate induces chemokine expression in microglia and astrocytes through activation of the P2Y6 receptor. J Immunol 2011, 186(6):3701-3709.

39. Takahashi K, Prinz M, Stagi M, Chechneva O, Neumann H: TREM2transduced myeloid precursors mediate nervous tissue debris clearance and facilitate recovery in an animal model of multiple sclerosis. PLOS med 2007, 4(4):e124

40. Johanson CE, Duncan JA 3rd, Klinge PM, Brinker T, Stopa EG, Silverberg GD: Multiplicity of cerebrospinal fluid functions: New challenges in health and disease. Cerebros fluid res 2008, 5:10.

41. Fadok VA, Bratton DL, Konowal A, Freed PW, Westcott JY, Henson PM: Macrophages that have ingested apoptotic cells in vitro inhibit proinflammatory cytokine production through autocrine/paracrine mechanisms involving TGF-beta, PGE2, and PAF. J Clin Invest 1998, 101(4):890-898.

42. Brandt E, Woerly G, Younes AB, Loiseau S, Capron M: IL-4 production by human polymorphonuclear neutrophils. J Leukoc Biol 2000, 68(1):125-130.

43. Cassiani-Ingoni R, Coksaygan T, Xue H, Reichert-Scrivner SA, Wiendl H, Rao MS, Magnus T: Cytoplasmic translocation of Olig2 in adult glial progenitors marks the generation of reactive astrocytes following autoimmune inflammation. Exp Neurol 2006, 201(2):349-358.

44. Magnus T, Coksaygan T, Korn T, Xue H, Arumugam TV, Mughal MR, Eckley DM, Tang SC, Detolla L, Rao MS, et al: Evidence that nucleocytoplasmic Olig2 translocation mediates brain-injury-induced differentiation of glial precursors to astrocytes. J Neurosci Res 2007, 85(10):2126-2137.

45. Comabella M, Imitola J, Weiner HL, Khoury SJ: Interferon-beta treatment alters peripheral blood monocytes chemokine production in MS patients. J Neuroimmunol 2002, 126(1-2):205-212.

46. Sabbatucci M, Purificato C, Fantuzzi L, Gessani S: Toll-like receptor cross-talk in human monocytes regulates CC-chemokine production, antigen uptake and immune cell recruitment. Immunobiology 2011, 216(10):1135-1142

47. Martinet Y, Bitterman PB, Mornex JF, Grotendorst GR, Martin GR, Crystal RG: Activated human monocytes express the c-sis proto-oncogene and release a mediator showing PDGF-like activity. Nature 1986, 319(6049):158-160.

48. Assoian RK, Fleurdelys BE, Stevenson HC, Miller PJ, Madtes DK, Raines EW, Ross R, Sporn MB: Expression and secretion of type beta transforming growth factor by activated human macrophages. Proc Natl Acad Sci USA 1987, 84(17):6020-6024. 
49. Molnarfi N, Benkhoucha M, Bjarnadóttir K, Juillard C, Lalive PH: Interferon- $\beta$ induces hepatocyte growth factor in monocytes of multiple sclerosis patients. PLoS One 2012, 7(11):e49882.

50. Liberto CM, Albrecht PJ, Herx LM, Yong WW, Levison SW: Pro-regenerative properties of cytokine-activated astrocytes. J Neurochem 2004, 89(5):1092-1100.

51. Scott A, Powner MB, Gandhi P, Clarkin C, Gutmann DH, Johnson RS, Ferrara N, Fruttiger M: Astrocyte-derived vascular endothelial growth factor stabilizes vessels in the developing retinal vasculature. PLoS One 2010, 5(7):e11863.

52. Paxinos $G$, Watson CR: The rat brain in stereotaxic coordinates. 5th edition. Amsterdam; Boston: Elsevier Academic Press; 2005.

53. Giulian D, Baker TJ: Characterization of ameboid microglia isolated from developing mammalian brain. J neurosci off j Soci Neurosci 1986, 6(8):2163-2178.

54. Pyo $H$, Jou I, Jung $\mathrm{S}$, Hong $\mathrm{S}$, Joe EH: Mitogen-activated protein kinases activated by lipopolysaccharide and beta-amyloid in cultured rat microglia. Neuroreport 1998, 9(5):871-874.

55. Lehner M, Holter W: Endotoxin-free purification of monocytes for dendritic cell generation via discontinuous density gradient centrifugation based on diluted Ficoll-Paque Plus. Int archives allergy immunol 2002, 128(1):73-76.

56. Park JW, Vahidi B, Taylor AM, Rhee SW, Jeon NL: Microfluidic culture platform for neuroscience research. Nat Protoc 2006, 1(4):2128-2136.

doi:10.1186/1756-6606-6-28

Cite this article as: Jeong et al:: Repair of astrocytes, blood vessels, and myelin in the injured brain: possible roles of blood monocytes.

Molecular Brain 2013 6:28.

\section{Submit your next manuscript to BioMed Central and take full advantage of:}

- Convenient online submission

- Thorough peer review

- No space constraints or color figure charges

- Immediate publication on acceptance

- Inclusion in PubMed, CAS, Scopus and Google Scholar

- Research which is freely available for redistribution 